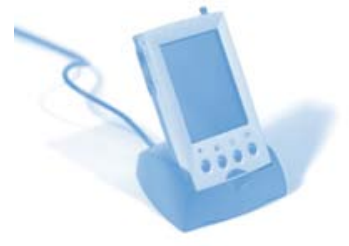

Orla C Kelly

Faculty of Education University of Plymouth

Drake Circus

Plymouth

PL4 8AA

orla.kelly@plymouth.ac.uk

\author{
Odilla E Finlayson \\ CASTeL \\ Dublin City University \\ Dublin 9 \\ Ireland
}

\section{Easing the transition from secondary school to higher education through recognition of the skills of our students}

\begin{abstract}
This short communication discusses research, which has investigated students' self-perception of their skills. This was to identify which skills they felt most and least confident in upon starting university. General and scientific and practical skills as well as skills related to improving learning were explored. The results suggested that students felt most confident in working in groups, interacting with people to obtain the necessary information and assistance, and observing chemical events and changes among others. In contrast students felt least confident in planning and presenting an oral presentation, analysing and evaluating experimental data, and using the internet and other resources to gain information. Details of how the findings were used to make effective changes to an existing module will be discussed. Furthermore, the relevance of this in terms of supporting our first year students in their transition to university-level work and subsequently planning appropriate modules will be discussed in relation to the recently published results from the UK Physical Sciences Centre Review of the Student Learning Experience in Chemistry and in light of the Department for Business Innovation and Skills Higher Ambitions and Skills for Growth papers.
\end{abstract}

\section{Background}

It is common practice to have a subject level entry requirement to university courses. In the sciences, it is typical that students have obtained at least a $C$ grade in an appropriate science subject at A-level, as well as a particular number of 'points'. For example, at the University of Plymouth, applicants to the BSc in Environmental Science degree are required to have $240-280$ points depending on subject combinations, which have to include a science subject to at least grade $\mathrm{C}$. However, despite ensuring a particular academic level of our entrants to higher education, we rarely audit their skills. This may result in us placing both subject knowledge and skills demands on our students, not least mathematics demands which are recognised as causing learning difficulties for students ${ }^{2}$. In the worst case we may expect them to have particular skills to enable them to make progress with their subject knowledge and understanding, resulting in them making little or no progress, coupled with a feeling of frustration. This is particularly pertinent with the recent shift towards context and problem-based learning approaches to teaching the physical sciences in Higher Education', which demand a range of skills from the students to enable them to make progress with their task set. This study aims to: (1) provide insight on what skills our students have upon starting university, drawing from both a small scale study carried out at Dublin City University and published literature, and (2) to consider the implications for our teaching of the physical sciences in Higher Education. A brief review of the current situation of practical work at upper secondary level is needed to provide insights into the students' experiences of practical work prior to starting university.

\section{Current situation of practical work at A-level and Leaving Certificate}

Current A-level science curricula in the UK offer students various elements of practical work but there is limited opportunity for independent or inquiry-based practical work in the school laboratory. Furthermore, in a recent study of undergraduate students' experiences of A-level practical work, it was reported that practical work was either conducted to verify theory, or as a vehicle for assessment. Reviewing the Irish chemistry and physics curricula for Leaving Certificate (A-level equivalent)', there are a number of experiments that the students are required to do, but again these are in the form of verification experiments or demonstration. With a verification approach the teacher defines the topic to be investigated, relates the investigation to previous work and directs the action of the students, with the students typically following directions from a manual. It is a popular time-, resource- and cost- effective approach allowing large numbers of students to access laboratory techniques and procedures. Verification experiments are not without their critics however. Indeed there has been much 


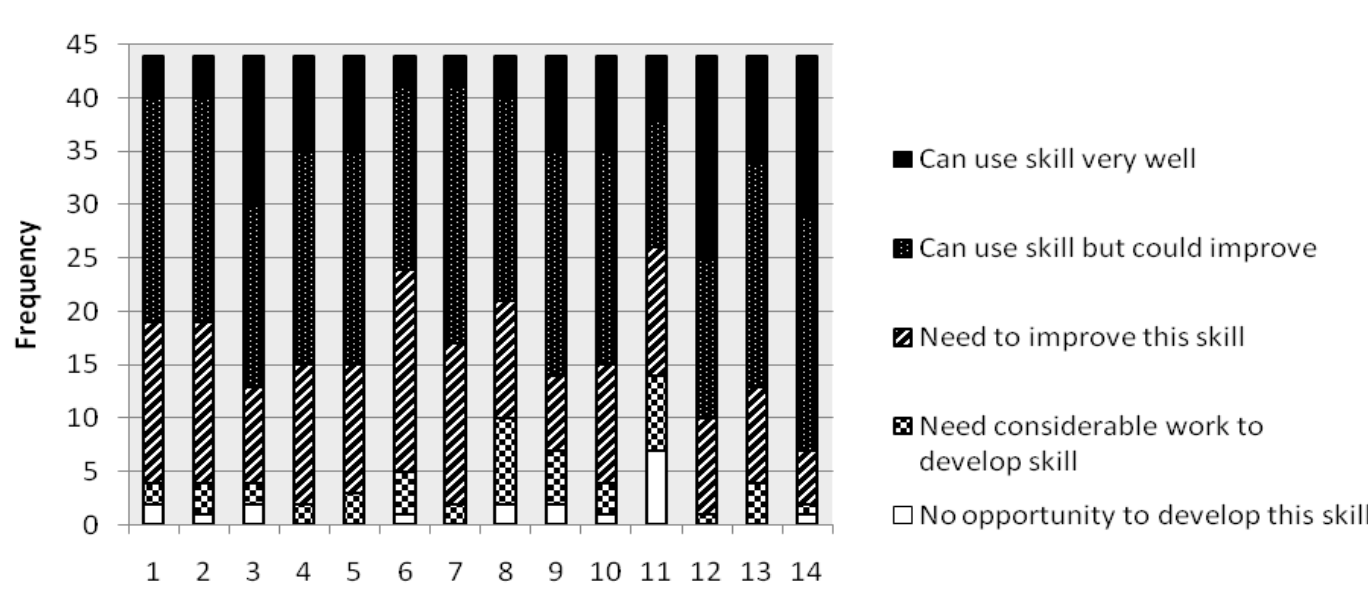

General skill statement

Figure 1: Bar chart of the frequencies of answers to the 14 general skills.

published on the disadvantages of these 'recipe' style laboratory experiments, not least the information overload that is placed on the students. However, evidence from the recent review of the student learning experience in chemistry in Higher Education ${ }^{2}$, shows clearly that year 1 and 2 undergraduate students prefer this type of practical work where the expected outcome is known and the procedures are familiar. It is only in Year 4 that $40 \%$ of students report a preference for practical work where they do not know the outcome and procedures have to be devised. Does this suggest that independent practical work such as inquiry or problem-based work in Year 1, presents too big a jump considering the experiences that our students bring from secondary school? With such a perceived risk, there must be considerable advantages in these alternative approaches in order for lecturers to adopt them in the early years of their programmes.

\section{Problem-based learning (PBL) in Higher Education}

When students are immersed in a PBL environment they are working in groups on problems that demand the acquisition of new knowledge and the use of a range of skills to solve the problems. The contextual element of the problem provides relevance and motivation for the students.

Problem based learning (PBL) is a style of learning in which the problems act as the context and driving force for learning. All learning of new knowledge is done within the context of the problems. PBL differs from problem solving in that in PBL the problems are encountered before all the relevant knowledge has been acquired and solving problems results in the acquisition of knowledge and problem-solving skills.

It is claimed that a PBL approach:

- produces more motivated students;

- develops a deeper understanding of the subject;

- encourages independent and collaborative learning;

- develops higher order cognitive skills;

- develops a range of skills which include problem solving, group working, critical analysis and communication. $^{2}$
Alternative approaches to science education, such as PBL, are also in response to calls for development of transferable and employability skills. The Dearing report as far back as 1997 noted the importance of developing key skills, cognitive skills and subject specific skills in Higher Education. More recently the Higher Ambitions and Skills for Growth strategies recognise the critical role universities play in equipping people with the skills they need to prosper in a knowledge economy and, that employers in all sectors need graduates with skills for the modern world of work. In particular it is recognised that 'the needs of growing markets like bioscience and low-carbon will require new and higher level skills' (p 4) This focuses the role that we, as science educators, have in preparing our students for the future demands of our society.

\section{Methodology}

Considering the demands for 'skilled' graduates and the promised outcomes of PBL, a problem-based approach was introduced to the Year 1 chemistry laboratory module taken by students on the BSc in Science Education at Dublin City University, Ireland. The rationale for development and the students' experience of this module have been previously described'. With the concern over the experiences of our students prior to starting university it was decided to carry out a skills audit of our Year 1 students on starting their university course. Students from the 2002-2003 and 2003-2004 cohorts were asked to complete the skills survey ( 44 students completed the survey). This was to identify what skills students felt they were confident in using, and which skills the students had little opportunity to develop. The module would then be tailored to enable the students to develop a full range of skills.

The survey was adapted from the RSC's Undergraduate Skills Record (USR). Various skills were identified in the USR which were seen to be important for first year undergraduate students, such as to interpret laboratory measurements and observations and to use feedback to improve on future work. The skills survey asked the students to rate a series of 26 skills on the basis of their confidence in performing each. The students rated their confidence in each of the skills on a scale 


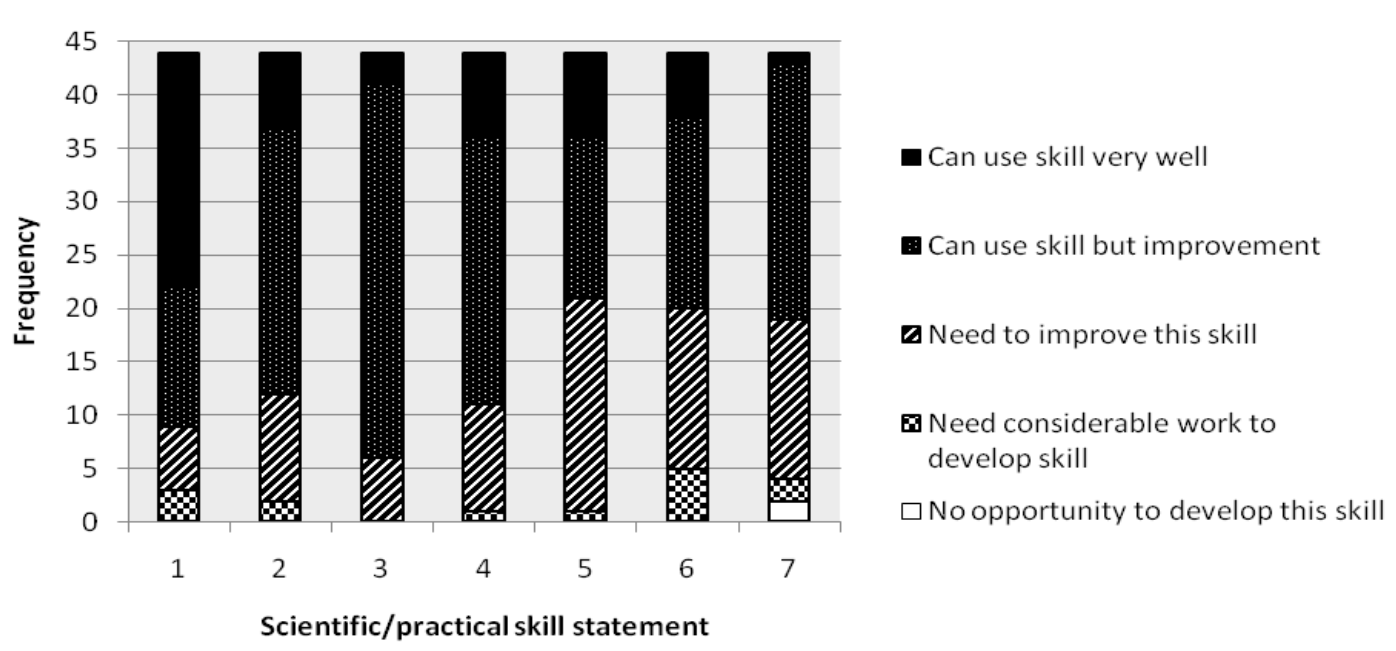

Figure 2: Bar chart of the frequency of answer to the 7 scientific/practical skills.

of 1 to 5 ; with 1 meaning they have had no opportunity to develop the skill to date and 5 meaning they can use the skill very well. The skills were separated into three key areas:

General skills (14 Statements);

Scientific/Practical skills (7 Statements);

Improving learning (5 Statements).

It is acknowledged and appreciated that this study was carried out in an Irish university, with students who had been through the Irish school system. However, it is hoped that the similarities between the experiences of Leaving Certificate and A-levels physical science students justify implications being drawn for the UK as well as Ireland.

\section{Results}

Figure 1 shows a bar chart of the frequencies of each answer for the general skills from the combined data for the two years. It is clear from the chart that students felt that they could apply skill 12 'work in groups' and skill 14 'interact with people to obtain the necessary information and assistance' with confidence. Skill 11 'Plan and present an oral presentation' was identified as the skill that the students have had the least opportunity to develop and felt least confident in, with skill 6 'analyse and evaluate experimental data' and skill 8 'interpret chemical information' respectively scoring second and third lowest.

Figure 2 shows a bar chart of the frequencies of each answer for the scientific and practical skills. In terms of these skills, students identified skill 1 'maintain awareness of specific hazards relating to chemicals' and skill 3 'understand the processes involved in experiments' as their most developed in this category. Students felt least confident in skill 7 'select appropriate techniques and procedure' and skill 6 'understand errors' as shown in Figure 2.

Figure 3 shows a bar chart of the frequencies of each answer for the improving learning skills. Students revealed that they felt most confident in skill 2 'maintaining an interest in general science issues' and least confident in skill 3 'using internet and other resources to gain information' and skill 4 'use computers to prepare reports/presentations'.

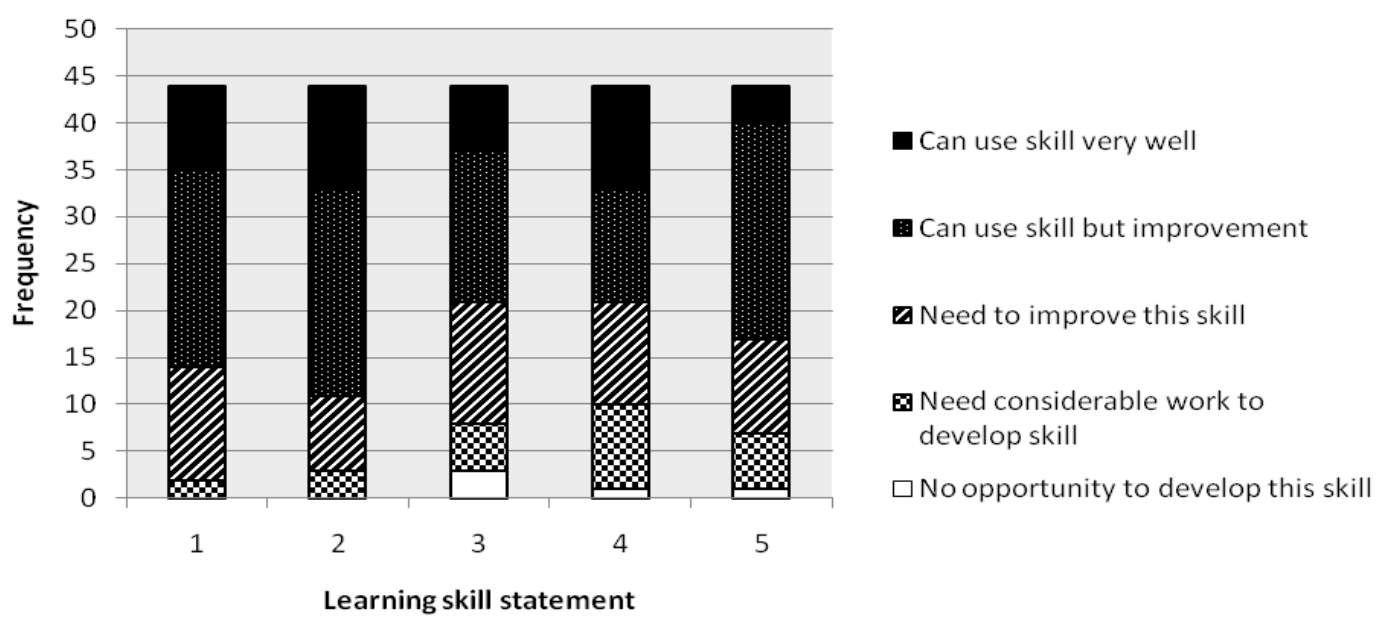

Figure 3: Description of skills to improve learning. 


\author{
Description of General skills statements \\ My ability to... \\ 1. Plan ahead and demonstrate good time management. \\ 2. Plan for practical work and project work. \\ 3. Make, organise, and store notes effectively. \\ 4. Make the most of group work, and tutorials to support \\ my understanding. \\ 5. Make the most of practical work to support my \\ understanding. \\ 6. Analyse and evaluate experimental data. \\ 7. Interpret laboratory measurements and observations. \\ 8. Interpret chemical information (i.e. chemical formulas, \\ equations etc.) \\ 9. Maintain good laboratory notes. \\ 10. Provide written reports on time. \\ 11. Plan and present an oral presentation. \\ 12. Work in groups (i.e. contributing in labs.) \\ 13. Assume a range of roles within a group. \\ 14. Interact with people to obtain necessary information \\ and assistance.
}

\section{Description of Scientific/Practical skills statements \\ My ability to...}

1. Maintain awareness of the specific hazards relating to chemicals.

2. Understand the principles behind experiments.

3. Understand the processes involved in experiments.

4. Measure and observe chemical events and changes.

5. Record experimental data coherently.

6. Understand errors.

7. Select appropriate techniques and procedures for experimental work.

\section{Description of Skills to Improve Learning}

My ability to...

1. Use feedback to improve on future work.

2. Maintain an interest in general science issues.

3. Use the internet and other resources to gain information.

4. Use computers to prepare reports/presentations.

5. Apply acquired knowledge to the solution of chemistry problems.

It is worth commenting on the limitations of this skills survey. Firstly, some of the students had limited practical experience, and therefore limited understanding of the statements. Also, it is a self-perception survey and so may not reflect the actual skills of these students. Despite these, it is a useful tool to begin to appreciate the strengths and weaknesses of the cohort's skills. This small-scale study was used to inform the development of the PBL module at Dublin City University, by focusing on tasks that develop particular skills further and build students' confidence in using a range of skills. Examples include incorporating oral (PowerPoint) presentations into the laboratories, and getting students involved with the development of experiments, by researching appropriate techniques and procedures using the internet and other resources. Also, the importance of errors and evaluating experimental data was a key focus of their write-ups and their oral presentations. This was done in a gradual way, increasing the skill demand across the year-long module.

\section{Discussion}

The UK Parliamentary Standing Committee on Science and Technology states '... school science can be so boring it puts young people off science for life. GCSE science students have to cram in so many facts that they have no time to explore interesting ideas, and slog through practical exercises which are completely pointless. This is a disaster: we need to encourage a new generation of young scientists ${ }^{19}$. This is exemplified by Abraham's research on motivation and practical work in school science which stated that 'the proportion of pupils, within each year group, who claim to like practical work in an 'absolute' sense, as against simply preferring it to writing, decreases as the pupils progress through the school. Indeed it would seem from the pupils' comments that, within their first year of secondary school, the novelty of being in a laboratory environment appears to wear off and they evidently become disillusioned by the reality of school science ( $p$ 2349-50).

This is not a situation unique to the UK. A recent review of school science education in Europe led to a number of recommendations relevant to this discussion, not least that more attempts at innovative curricula and ways of organising the teaching of science that address the issue of low student motivation are required and that the emphasis in science education should be on engaging students with science and scientific phenomena. Evidence suggests this is best achieved through opportunities for extended investigative work and 'hands-on' experimentation ${ }^{22}$. If things change for school level science this should mean that our future science undergraduates will enter our courses with more developed skills. However, in the mean time, it is essential that the skills level of our students is recognised on starting their university degree programme. Moreover, on recognising deficiencies in their skills, we need to give our students experience in developing these areas.

It is interesting that in the recent UK Physical Sciences Centre review ${ }^{2}$ it was noted that chemistry teaching staff recognised that 'the weakness in problem-solving ability stems from the difference in teaching methods between schools and universities...universities expect independent learners, whereas school students are teacher-led' ( $p 26)$, yet 'fewer departments than might be expected have a specific strategy to develop the problem-solving abilities of students' ( $p$ 42). Careful planning and consideration are needed to develop skills from within programmes and it should not be assumed that students will naturally do this. Additionally, research by Slaughter and Bates who investigated students attitudes and beliefs found that over the course of the first year of a physics degree programme, students became 'more novice-like in' 11 areas and 'more expert in 2' ( $p$ 37). The two areas that students became more expert-like in were both issues that were specifically addressed by the course design. This supports the notion that we must actively seek to develop particular skills and embed support within our programmes and modules.

In summary, we need to continue to push for more innovative curricular in school science, which support the development of skills, acquisition of knowledge and development of understanding and to continue these innovative curricula in higher education. Furthermore, we need to be aware of the skills of our students and provide appropriate experiences for them to develop and expand their skills so they can emerge 
as graduates with the attributes, attitudes and skills to contribute successfully to the knowledge economy and be responsible citizens with the scientific literacy to engage with the debates that the future will bring.

\section{References}

1. University of Plymouth (2010) BSc (Hons) Environmental Science

<www.plymouth.ac.uk/courses/undergraduate/0074/ BSc\%20(Hons)\%20Environmental\%20Science> [Accessed 28/5/2010]

2. UK Physical Science Centre (2009) Review of the Student Learning Experience in Chemistry. Hull: Higher Education Academy UK Physical Sciences Centre.

3. Overton, T.L., Byers, B. And Seery, M.K. (2009) Context- and problem-based learning in higher level chemistry education in I. Eilks and B. Byers (Eds.) Innovative Methods in Teaching and Learning Chemistry in Higher Education. Cambridge: Royal Society of Chemistry, 43-60.

4. Belt, S.T. (2009) Impacts of assessment in problem-based learning: A case study from chemistry. New Directions in the Teaching of Physical Sciences, $\mathbf{5}$, 16-21.

5. A levels (2010) Qualifications and Curriculum Development Agency <www.qcda.gov.uk/qualifications/27.aspx> [Accessed 28/5/2010]

6. Kelly, O. and Cutting, R.L. (2008) Going up alleys to see if they are blind: The use of problem-solving as basis for teaching undergraduate science programmes. In Cavas, B. (Ed.). The Use of Science and Technology Education for Peace and Sustainable Development. Proceedings of 13th IOSTE Symposium, Kusadasi (Turkey), Palme Publications, Ankara. 944-952. Available at: $<w w w . i o s t e . o r g / p d f / p r o c e e d 13 . p d f>$

7. Leaving Certificate Chemistry Syllabus (1999)

Department of Education and Science

$<$ www.curriculumonline.ie/uploadedfiles/PDF/

Ic_chemistry_sy.pdf>

[Accessed 28/5/2010]

8. Leaving Certificate Physics Syllabus (1999) Department of Education and Science

$<$ www.curriculumonline.ie/uploadedfiles/PDF/

Ic_physics_sy.pdf>

[Accessed 28/5/2010]

9. Domin, D. (1999) A review of laboratory learning styles. Journal of Chemical Education, 76 (4), 543-547.

10. Montes, L.D. and Rockley, M.G. (2002) Teacher Perceptions in the Selection of Experiments, Journal of Chemical Education, 79 (2), 244-247.

11. Johnstone, A.H. (1997) Chemistry Teaching - Science or Alchemy? 1996 Brasted Lecture. Journal of Chemical Education, 74 (3), 262-268.

12. UK Physical Sciences Centre (2005) Problem-based learning: An introduction.

$<w w w . h e a c a d e m y . a c . u k / a s s e t s / p s / d o c u m e n t s / p r i m e r s /$ primers/

ps0087_problem_based_learning_mar_2005.pdf>

[Accessed 31/05/2010]
13. Dearing, R. (1997) Higher Education in the Learning Society. National Committee of Inquiry into Higher Education.

$<$ www.leeds.ac.uk/educol/ncihe/>

[Accessed 29/05/2010]

14. Department for Business Innovation and Skills (2009a) Higher Ambitions - the future of universities in a knowledge economy. Executive summary. $<$ www.bis.gov.uk/assets/biscore/corporate/docs/h/091452-higher-ambitions-summary.pdf> [Accessed 29/05/2010]

15. Department for Business Innovation and Skills (2009b) Skills for Growth - the national skills strategy. Executive summary. $<$ www.bis.gov.uk/assets/biscore/corporate/docs/s/skillsstrategy-summary.pdf> [Accessed 29/05/2010]

16. Kelly, O.C. and Finlayson, O.E. (2007) Providing solutions through problem-based learning for the undergraduate $1^{\text {st }}$ year chemistry laboratory, Chemistry Education Research and Practice, 8 (3), 347-361.

17. Kelly, O.C. and Finlayson, O.E. (2009) A hurdle too high? Students' experience of a PBL laboratory module. Chemistry Education Research and Practice, 10 (1), 42-52.

18. Undergraduate Skills Record (2005) Royal Society of Chemistry $<$ www.rsc.org/Education/HEstudents/usr/index.asp > [Accessed 28/5/2010]

20. Abrahams, I. (2009) Does practical work really motivate? A study of the effective value of practical work in secondary school science. International Journal of Science Education, 31 (17), 2335-2353.

21. Osborne, J. and Dillon, J. (2008) Science Education in Europe: Critical Reflections. A report to the Nuffield Foundation. The Nuffield Foundation, London. $<$ www.nuffieldfoundation.org/fileLibrary/pdf/ Sci_Ed_in_Europe_Report_Final.pdf> [Accessed 18/05/2010]

22. Slaughter, K. And Bates, S. (2009) Mapping the transition - content and pedagogy across the school-university boundary, New Directions in the Teaching of Physical Sciences, 5, 35-39. 